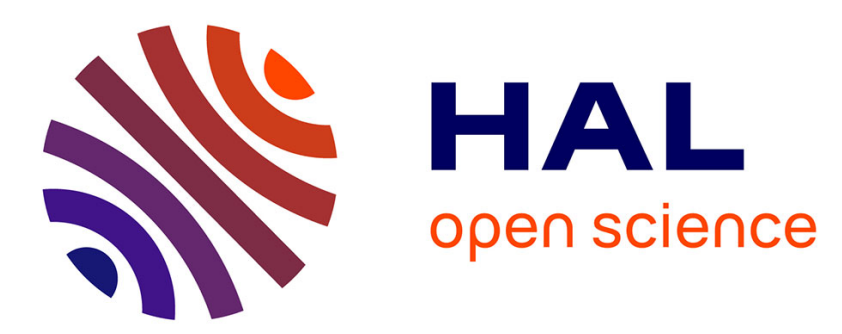

\title{
Fracture and Cohesive Parameter Identification of Refractories by Digital Image Correlation Up to $1200^{\circ} \mathrm{C}$
}

Aurélien Doitrand, R. Estevez, M. Thibault, P. Leplay

\section{To cite this version:}

Aurélien Doitrand, R. Estevez, M. Thibault, P. Leplay. Fracture and Cohesive Parameter Identification of Refractories by Digital Image Correlation Up to $1200^{\circ} \mathrm{C}$. Experimental Mechanics, 2020, pp.577-590. 10.1007/s11340-020-00584-7 . hal-02780559

\section{HAL Id: hal-02780559 \\ https://hal.science/hal-02780559}

Submitted on 11 Mar 2021

HAL is a multi-disciplinary open access archive for the deposit and dissemination of scientific research documents, whether they are published or not. The documents may come from teaching and research institutions in France or abroad, or from public or private research centers.
L'archive ouverte pluridisciplinaire HAL, est destinée au dépôt et à la diffusion de documents scientifiques de niveau recherche, publiés ou non, émanant des établissements d'enseignement et de recherche français ou étrangers, des laboratoires publics ou privés. 


\title{
Fracture and cohesive parameter identification of refractories by Digital Image Correlation up to $1200^{\circ} \mathrm{C}$
}

\author{
A. Doitrand · R. Estevez - M. Thibault • P. Leplay
}

Received: 2019 / Accepted: date

\begin{abstract}
The mechanical and fracture properties of refractory ceramics are determined by means of an inverse identification procedure between experimental data and numerical simulations. An experimental set-up is proposed to perform Wedge Splitting Tests (WST) at elevated temperature with Digital Image Correlation (DIC) to assess the crack propagation. The ceramic Young's Modulus, fracture energy and strength are determined by indirect confrontation to Finite Element simulations of crack propagation in WST specimens employing Cohesive Zone Modeling $(\mathrm{CZM})$. The variations of the force and crack length are used to set an inverse problem for estimating the material parameters for various temperatures. The method, illustrated through the analysis of an industrial refractory ceramic from $25^{\circ} \mathrm{C}$ to $1200^{\circ} \mathrm{C}$, combines experimental and numerical approaches to understand and optimize the fracture behaviour of refractories in application.
\end{abstract}

Keywords Cohesive Zone Model · Refractories · Fracture - Digital Image Correlation · Wedge Splitting Test • High Temperature

\section{Introduction}

Refractory ceramics are widely employed in parts that are used in high temperature environments such as, e.g., glass furnaces, steel ladles or blast furnaces. These parts are subjected to severe thermal gradients that may provoke the initiation and propagation of cracks. The presence of such cracks is critical since they may weaken the whole structure and locally enhance the corrosion effects, leading to a lifetime reduction of the furnaces.

A major challenge thus consists in predicting the initiation and propagation of such cracks. To this end, modeling the temperature distribution within the part as well as providing realistic description of failure can help in the definition of a robust design. These models require some essential parameters such as the refractory fracture properties (critical energy release rate and strength) and also their variations from room temperature to really high temperature (up to $1500^{\circ} \mathrm{C}$ ).

Aurélien Doitrand, Rafael Estevez

Université Grenoble-Alpes - CNRS UMR 5266, SIMaP, F-38000 Grenoble, France

Tel.: +33-76-826688

E-mail: aurelien.doitrand@simap.grenoble-inp.fr

E-mail: rafael.estevez@simap.grenoble-inp.fr

Paul Leplay, Marielle Thibault

Saint-Gobain Research Provence, F-84300 Cavaillon, France

E-mail: paul.leplay@saint-gobain.com

E-mail: marielle.thibault@saint-gobain.com 


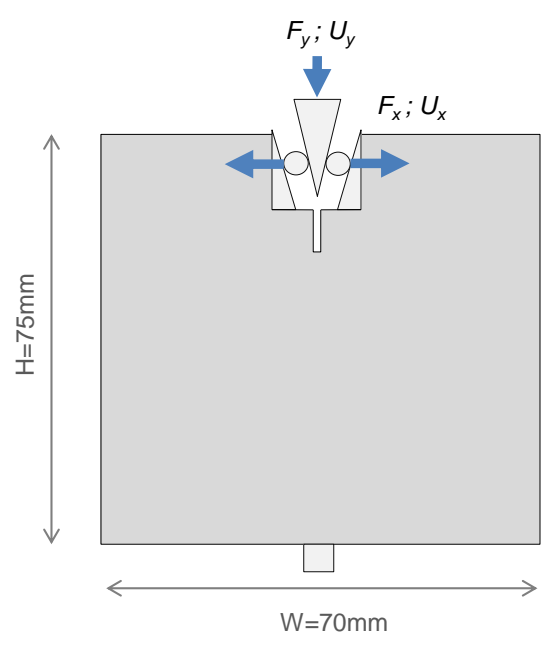

Fig. 1 Scheme of a Wedge Splitting Test

The Wedge Splitting Test (WST) is commonly employed to study failure of ceramic materials, especially in case of coarse microstructures [1-3].

A notched specimen placed on a support is subjected to a vertical force which is transformed to a horizontal force through load transmission equipment (wedge and cylinders) (Fig. 1), which induces stable crack propagation in specimens with sufficiently large dimensions [4]. More details about the WST are given, e.g., in [5-7]. The WST allows the specimen fracture energy to be measured based on the load-displacement curve and the crack surface at the end of the test $[4,5,8,9]$. In practice, the test has to be stopped at a certain percentage threshold of the maximum force in order to avoid any contact between the wedge and the sample [9]. However, the validity of this method is limited to cases for which the results do not depend on the choice of this final threshold. The material fracture parameters can also be determined through inverse identification [10-16], which exploits the whole test data instead of only data extracted from a state at the end of the test. These identifications may be based either on analytical [10,12-14] or Finite Element (FE) [11,15-17] models. For instance, Vargas et al. recently proposed a Finite Element Model Updating (FEMU) approach for the identification of the fracture parameters of a refractory castable at room temperature $[15,16]$. Except for the latter references, these approaches usually concern the macroscopic force-displacement response but do not account for crack length variation as a function of the prescribed loading.

A convenient tool to capture the kinematics of the crack propagation during the test is Digital Image Correlation (DIC) $[8,15,18,19]$ which is an in-situ full-field displacement method [20-22]. DIC was already used as an instrumentation of WST. Belrhiti et al. [8] used DIC so as to track the development of a network of micro-cracks and its influence on the force-displacement response depending on the material microstructure. Dai et al. [18] employed DIC in order to observe and quantify the fracture process zone of magnesia refractories. In some cases they observed crack branching that increases the specific fracture energy. The same authors showed that the crack growth resistance is almost independent of the crack length as long as the fracture process zone does not interact with the edge of the specimen [9]. Crack detection in WST using adapted DIC that take into account displacement discontinuities at cracks was also performed by Dupré et al. [23]. Some crack branching phenomena leading to a longer crack network were highlighted and linked to a higher energy dissipation. Vargas et al. [15] compared two 


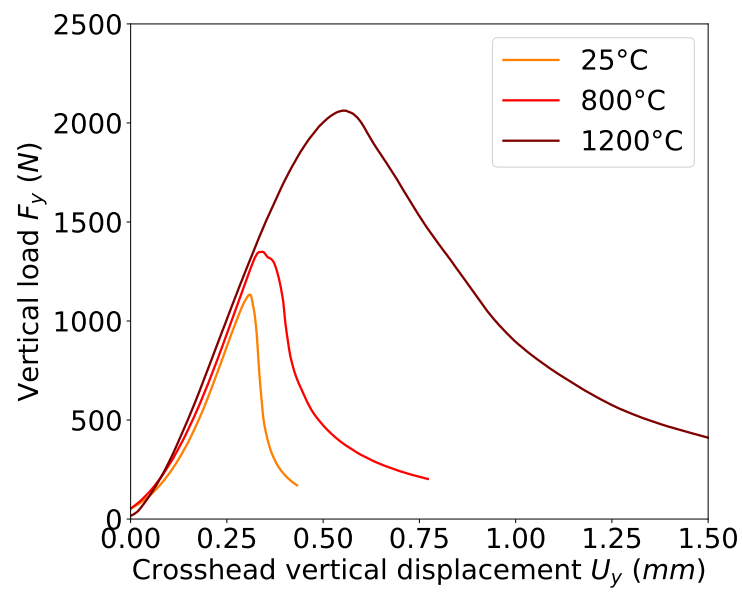

Fig. 2 Load-displacement response depending on the temperature

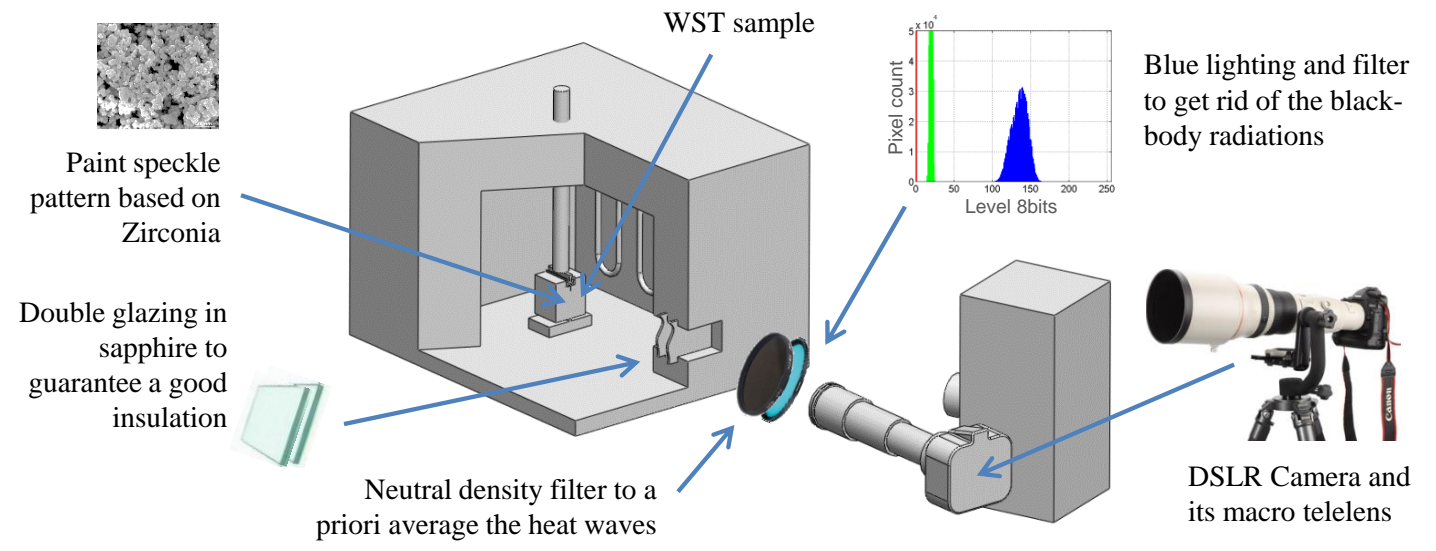

Fig. 3 Experimental set-up to run WST test with Digital Image Correlation up to $1200^{\circ} \mathrm{C}$

full-field identification methods, namely finite element model updating and integrated-DIC. Both methods allowed the crack tip location to be estimated, which appears to be a key feature in such procedures.

In the aforementioned references, WST were performed employing DIC at room temperature. However, the development of lifetime prediction models of industrial furnaces requires the characterization of the material properties at several elevated temperatures. This work is focused on the experimental characterization of refractory fracture properties at high temperature. The paper is organized as follows: The experimental set-up with DIC up to $1200^{\circ} \mathrm{C}$ is described in Section 2. An inverse identification procedure for WST that allows the material fracture parameters to be identified is presented in Section 3. In Section 4, this procedure is applied to an industrial refractory in order to quantify its increasing fracture resistance from $25^{\circ} \mathrm{C}$ to $1200^{\circ} \mathrm{C}$. 


\section{Experimental set-up of the wedge splitting test with DIC}

\subsection{Mechanical test}

The studied material is a refractory ceramic made by Saint-Gobain SefPro for glass furnace application. This material, made with several oxide ceramics, has a heterogeneous microstructure with some millimetric grains. The size of the studied specimens which contain an initial notch is $75 \mathrm{~mm} \times 70 \mathrm{~mm} \times 65 \mathrm{~mm}$. These WST specimens do not have a lateral groove to guide the crack propagation so that the fracture process zone is free to expand in $3 \mathrm{D}$ as in application. An electrical furnace is used to heat the sample at a rate of $200^{\circ} \mathrm{C}$ per hour. The final temperature (up to $1200^{\circ} \mathrm{C}$ ) homogeneity around the sample is controlled with three thermocouples, the temperature measurerement uncertainty being $\pm 5^{\circ} \mathrm{C}$. The crosshead speed is set at $0.1 \mathrm{~mm} / \mathrm{min}$ and the load is transferred to the sample through a wedge with an angle of $\beta=20^{\circ}$. The test is conducted until the load drops to $15 \%$ of the maximal reached load. From $25^{\circ} \mathrm{C}$ to $1200^{\circ} \mathrm{C}$, one can observe the different load-displacement responses depending on the temperature (Fig. 2). The area under the force-displacement curve, which is related to the material critical energy release rate, increases with the temperature so as to limit the propagation of the crack towards the interior of the specimen.

\subsection{DIC at high temperature}

The central zone of the sample is observed using a digital single-lens reflex camera and a 300mm telelens (Fig. 3). Given the sensor parameters $(22.3 \mathrm{~mm} \times 14.9 \mathrm{~mm}, 4.5 \mathrm{M}$ pixel $)$, it results in a $28.3 \mu \mathrm{m} /$ pixel physical resolution. The images are acquired with a $0.2 \mathrm{~Hz}$ frequency. To be able to run DIC at high temperature, three main challenges must be addressed as explained in literature $[21,22,24,25]$ :

o First, a speckle pattern must be added on the sample surface to enhance the contrast [26] and perform DIC measurements. Laser speckle can be used [27] but the most direct approach consists in using a paint pattern which has to resist at high temperature and must not chemically interact with the oxide ceramic. Since most of the standard paints cannot withstand the range of temperature under consideration, a white solution based on zirconium oxide is made and spread on the samples, leading to a speckle pattern correlation radius about 4 pixels (i.e. about $113 \mu \mathrm{m})$.

o Second, the black-body radiation must be addressed to ensure a sufficient optical contrast above $800^{\circ} \mathrm{C}$ when the radiation level increases dramatically. A solution consists in using a blue light associated to a blue filter $[22,51]$. In these wavelengths smaller than $500 \mathrm{~nm}$, the radiation intensity remains quite reasonable so that a $15 \mathrm{~W}$ blue LED is sufficient to lighten correctly our samples.

o Third, severe optical distortions appear on the camera during the heat haze effect that might be quite important in such closed furnaces. One can try to reduce these distortions with fans or air knifes [28], with a very well insulated furnace associated to a slight gas sweeping [29] or to a partial vacuum [30]. Another solution consists in taking hundreds of pictures to construct averaged images [31] that can be analyzed using a DIC method based on an a priori spatial and temporal regularization [32-34]. It is also possible to a posteriori remove the noise brought by the heat haze $[27,35]$. We choose here to use neutral density filters to increase the exposure duration so that each image is directly an average of hundreds of instants. In previous studies, it was shown 


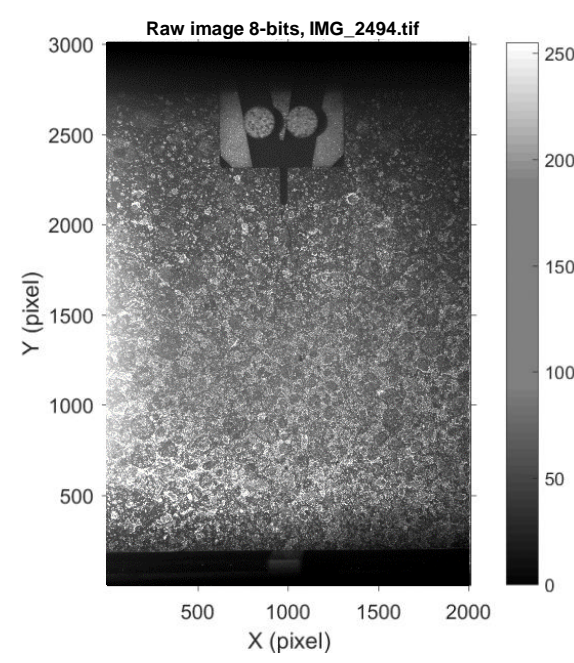

(a)

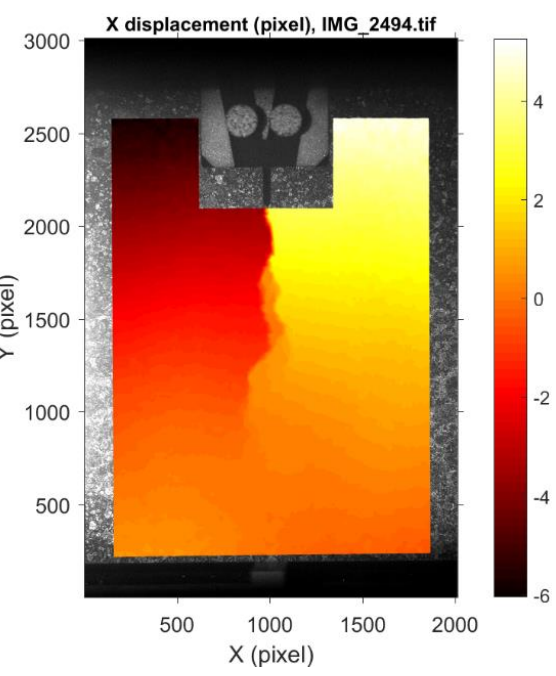

(b)

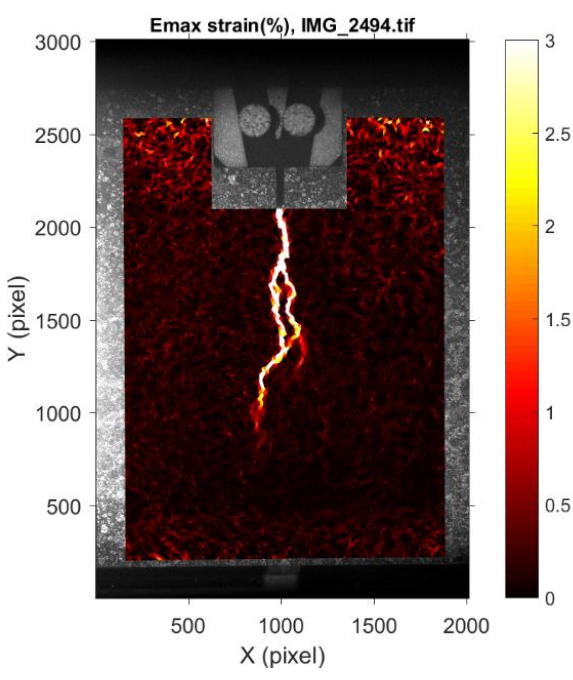

(c)

Fig. 4 DIC at $1200^{\circ} \mathrm{C}$ : from the raw image (a) to the horizontal displacement (b) and the first principal strain (c) fields.

that an exposure duration of at least few seconds was sufficient to decrease the measurement uncertainty due to heat haze $[21,36]$. We choose an exposure duration of 4 seconds, which is long enough to minimize the heat haze effect and short enough to well capture the crack propagation that will last around 10 minutes in our case.

The recorded images are analyzed with a global approach of DIC based on finite-element shape function [20] using a software developed by EikoSim ${ }^{\mathrm{TM}}$. Some specific DIC methods have been developed for brittle failure $[37,38]$ or quasi-brittle failure $[23,39,40]$. A T3 mesh is chosen with small enough elements (about 20 pixels in this case) ensuring a satisfactory crack detection and reasonable uncertainties which respectively vary from 0.05 to 0.5 pixel for the displacements and from $0.05 \%$ to $0.15 \%$ for the strains from room to high temperature. The maximal principal strain is extracted plotted element by element to avoid any smoothing around the crack path. Strain fields are given at three different temperatures in Figure 5. One can notice that the crack is almost straight at $25^{\circ} \mathrm{C}$, which is typical for a brittle behavior. At $800^{\circ} \mathrm{C}$, the material becomes a little bit more quasi-brittle but the crack path obtained using DIC remains quite straight. At the largest temperature, $1200^{\circ} \mathrm{C}$, the material is definitely quasi-brittle due to the evolution of its microstructure so that a very complex crack path is observed with many branching in the fracture process zone. The tortuosity of the cracks can be explained by the microstructure heterogeneity of the studied material and does not originate from loading asymmetry since the cracks remains quite vertical. WST tests associated to DIC enable well to distinguish and understand the variation of the fracture behavior of refractory with temperature. To be able to quantify the material response for this fracture test, several quantities can be extracted from DIC results as detailed in next section.

\subsection{Horizontal opening measurement}

The horizontal displacement of the two rollers can be determined analytically from the wedge angle $\beta$ and the magnitude of the crosshead vertical displacement. However, this value is not reliable due to the stiffness of the whole column and the numerous plays in the crosshead. The relative displacement of the rollers may be directly 

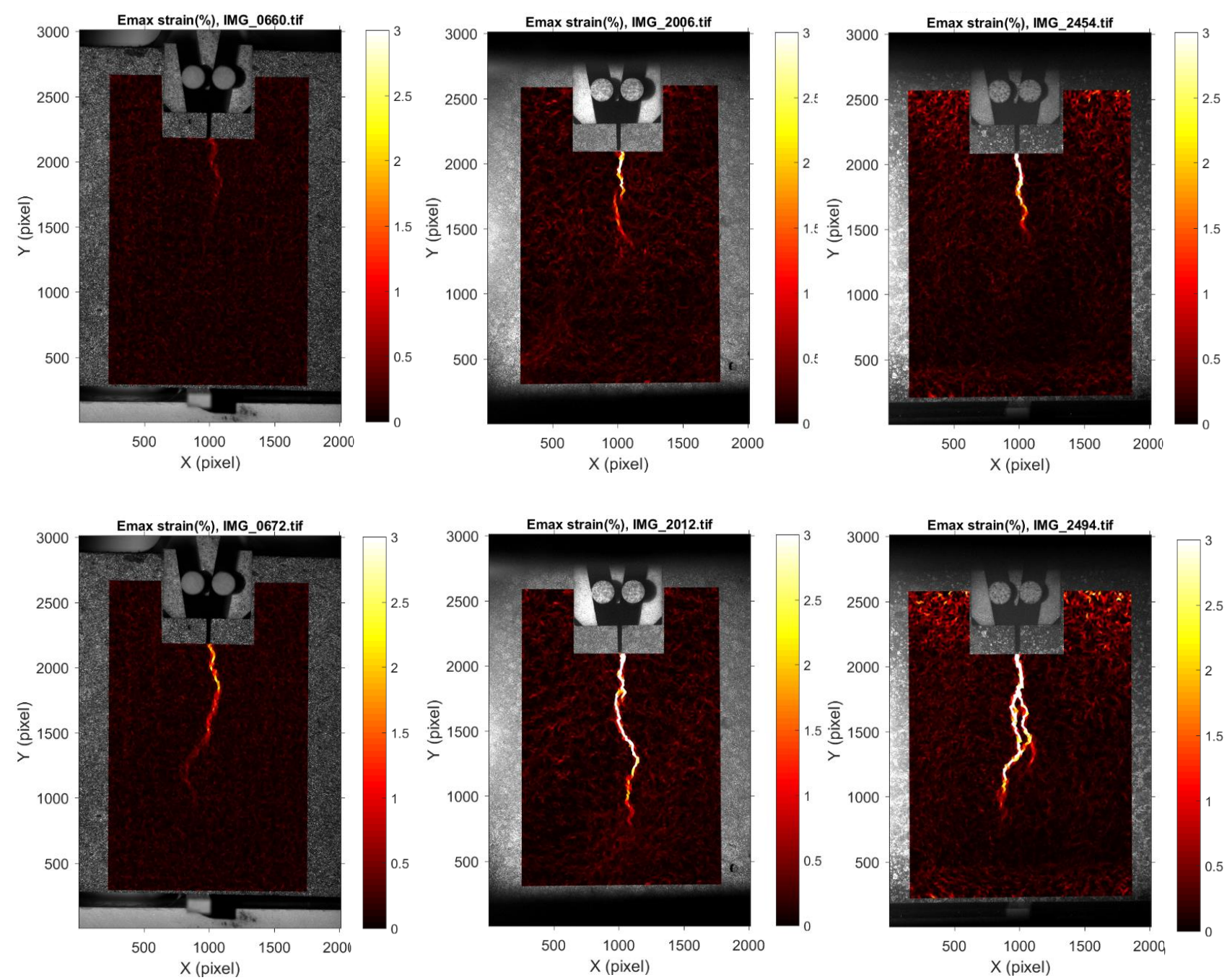

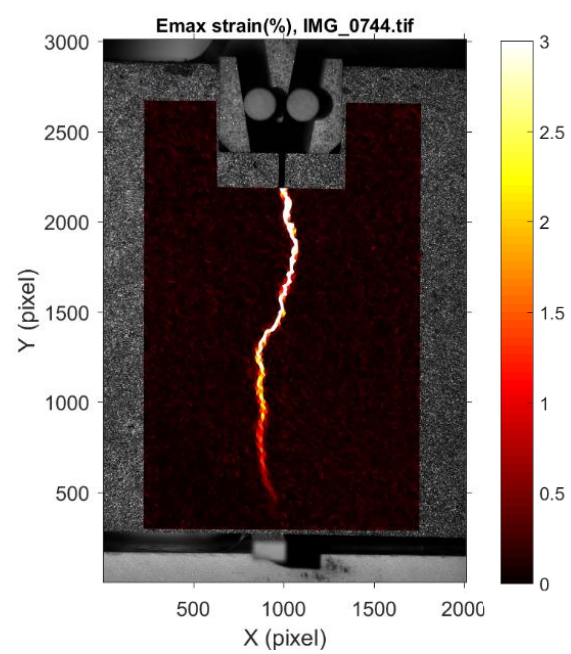

(a) $25^{\circ} \mathrm{C}$

$\mathrm{F}_{\mathrm{y}}=1122 \mathrm{~N}, 708 \mathrm{~N}$ and $170 \mathrm{~N}$

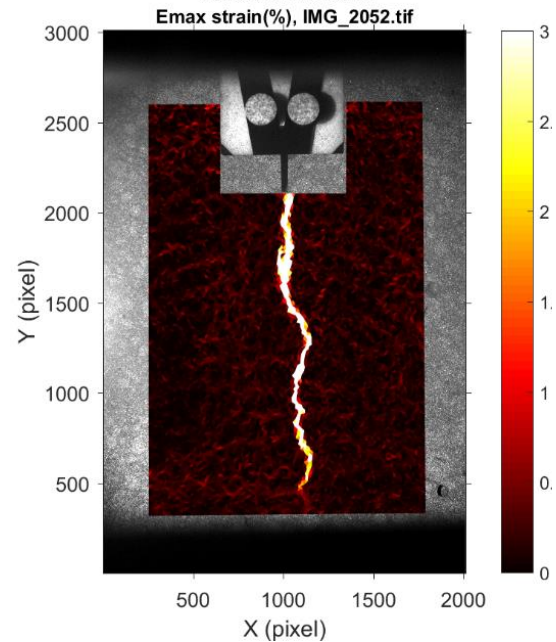

(b) $800^{\circ} \mathrm{C}$

$\mathrm{F}_{\mathrm{y}}=1187 \mathrm{~N}, 642 \mathrm{~N}$ and $203 \mathrm{~N}$

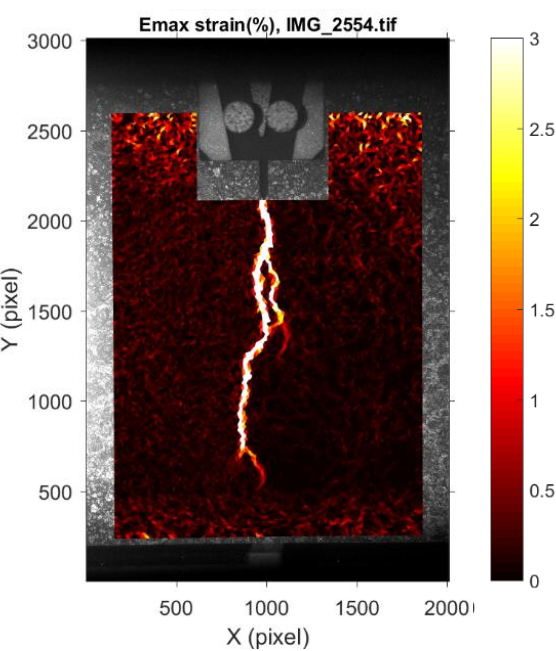

(c) $1200^{\circ} \mathrm{C}$

$\mathrm{F}_{\mathrm{y}}=1724,843 \mathrm{~N}$ and $402 \mathrm{~N}$

Fig. 5 First principal strain fields measured at different load steps for $25^{\circ} \mathrm{C}(\mathrm{a}), 800^{\circ} \mathrm{C}$ (b) and $1200^{\circ} \mathrm{C}$ (c) 


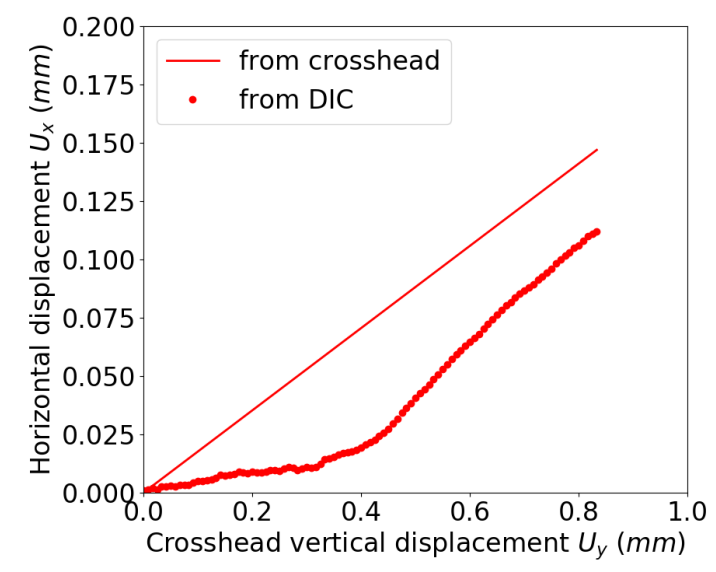

(a)

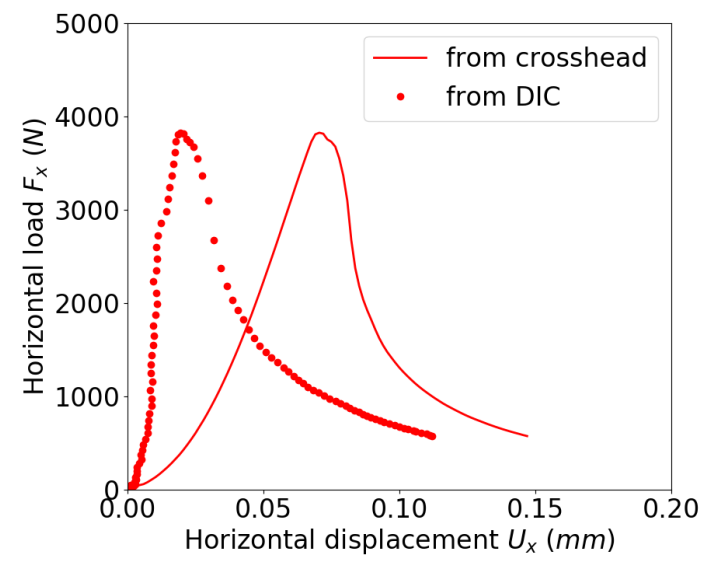

(b)

Fig. 6 Horizontal displacement of the rollers as a function of the vertical displacement either of the crosshead or obtained from DIC (a) Horizontal load versus horizontal displacement at $800^{\circ} \mathrm{C}$.

measured at room temperature with a LVDT apparatus, at high temperature with laser extensometer, or based on edge detection method [52]. In the present work, we use the DIC fields on the sample to estimate the displacement of the rollers by extracting the average displacement of two zones located near the two top angles of the region of interest (Fig. 4). In the elastic part of the force-displacement curve, the crosshead displacement is four times larger than the displacement measured by DIC. The difference decreases as the test continues so that the load decreases and the roller displacement increases. As already reported in the literature, this illustrates again how DIC allows the real displacements and thus boundary conditions to be captured $[15,41]$.

\subsection{Crack length measurement}

The extent of a crack or of a crack process zone can be estimated from the strain field distribution (Fig. 5) by considering a threshold value above which the local strain is so large that it corresponds to a given displacement jump. This provides a rough estimate of the crack extent but has many drawbacks from an identification point of view. First, the crack length might be quite dependent on the chosen strain threshold. Second, the estimated length does not necessarily correspond to the location where a real crack is created (i.e. traction-free surfaces), because of a possible fracture process zone that can be up to few $\mathrm{cm}$ long in refractory materials. Therefore, a cohesive zone model (CZM) (cf., e.g., [42]) is used to capture the transition from an undamaged bulk to a crack with full account for the displacement jump and non-zero tractions in the process zone. In the case of CZM, a crack nucleates locally at the end of the cohesive process zone for a critical displacement jump $\delta_{c}$ between two surfaces. This critical displacement jump is related to the material critical energy release rate $G_{\mathrm{c}}$ and strength $\sigma_{\mathrm{c}}$ (which corresponds to the magnitude of the tractions at the onset of debonding) as well as the traction-separation profile of the CZM. In the case of a bilinear model, it is given by $\delta_{c}=\frac{2 G_{\mathrm{c}}}{\sigma_{\mathrm{c}}}$. However the fracture parameters $G_{\mathrm{c}}$ and $\sigma_{\mathrm{c}}$ are not known a priori but are identified by comparison between numerical prediction and experimental data. Therefore, to be consistent with the CZM crack definition and allow the comparison of the experimental data with numerical predictions using several couples $\left(G_{\mathrm{C}}, \sigma_{\mathrm{c}}\right)$, the full displacement jump profile has to be measured along the crack path to be able afterwards to follow the point for which the displacement jump corresponds to the one identified. Hence, the identification will be based on numerical and experimental data that share the same definition 


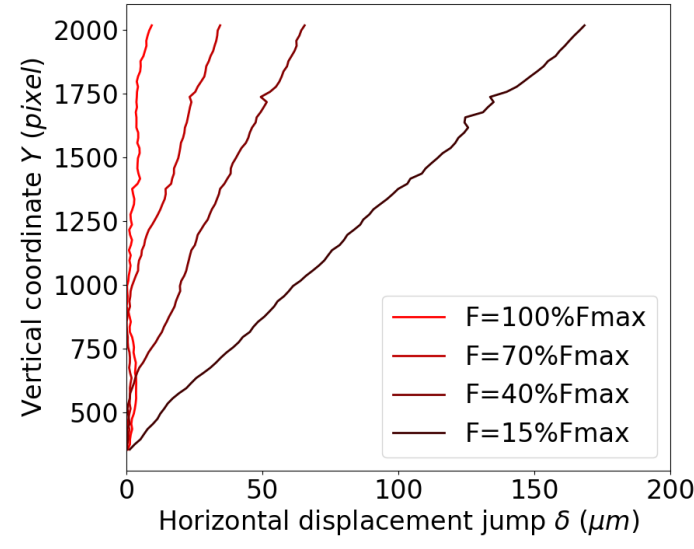

(a)

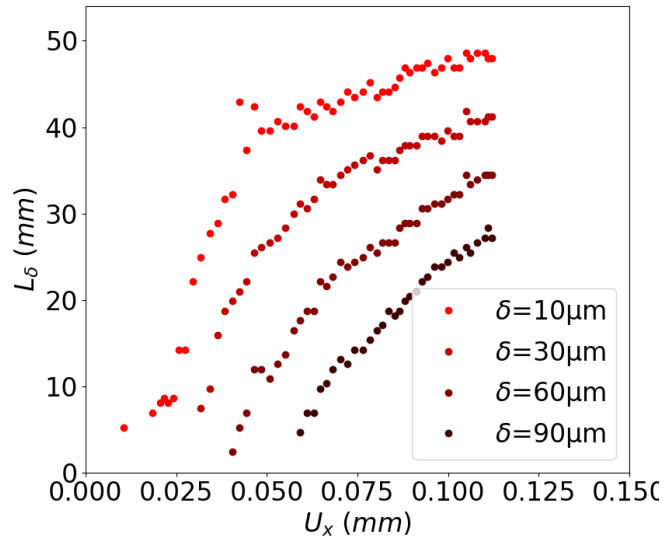

(b)

Fig. 7 Variation of the displacement jump profile (a) and crack length depending on the critical displacement jump (b)

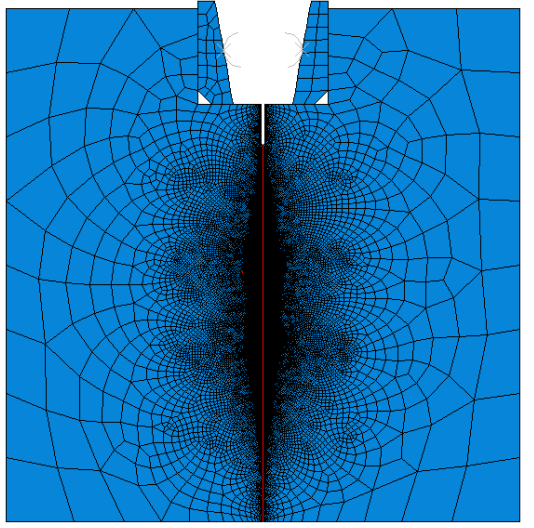

(a)

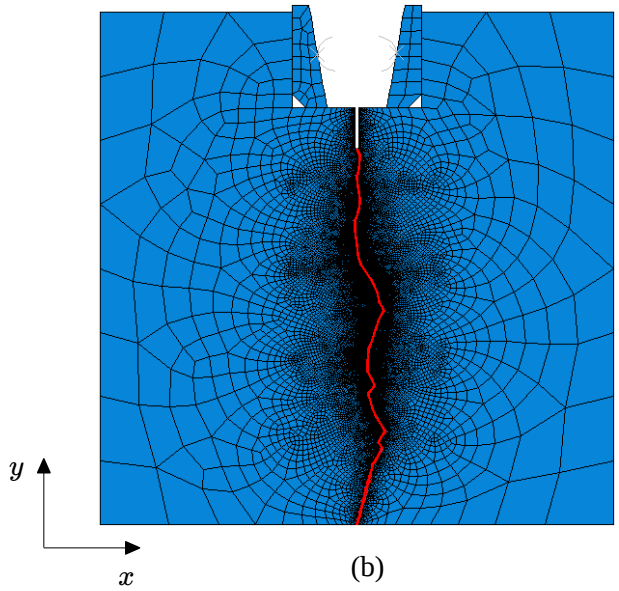

(b)

Fig. 8 Typical finite element mesh employed for the numerical calculations of force and crack length variations in the case of (a) a straight and (b) a tortuous crack. The cohesive zone elements are highlighted in red.

of a crack regarding a given value of displacement jump. The displacement jump profile is extracted from the DIC displacement fields knowing a posteriori the final main crack path. This is done by computing the displacement difference between each side of the crack (which path is initially guessed based on strain maps shown in Fig. 5). The measured crack length thus depends on the critical displacement jump $\delta_{\mathrm{c}}$ chosen in the identification procedure. An example of displacement jump and crack length measurement for several critical displacement jumps is presented in Fig. 7. Fig. 7a shows the position along the crack (vertical coordinate $Y$ ) as a function of the corresponding horizontal displacement jump $\delta$ for several loading levels. Fig. 7b shows the corresponding crack lengths as a function of the horizontal displacement of the cylinders obtained for several critical displacement jumps. It is clear that for a given horizontal displacement, the crack length measured experimentally depends on the critical displacement jump. This ensures that the crack lengths measured experimentally and obtained numerically share the same definition. 


\section{Numerical modeling and identification procedure}

\subsection{Finite element model of the WST}

The inverse identification procedure presented in Section 3.2 requires the computation of the force and crack length variations as a function of the prescribed displacement. This is done by means of $2 \mathrm{D}$ quasi-static FE calculations in Abaqus ${ }^{\mathrm{TM}}$. The specimen is discretized using 2D plane strain 4 nodes linear elements. Spans are modeled as analytical rigid body on which displacements are prescribed. A hard contact is modeled between the spans and the lateral wedges as well as between the lateral wedges and the specimen. The crack is modeled using cohesive zone elements along a predefined path. The employed cohesive zone model (CZM) describes the traction-separation relation between two surfaces. It consists of a first part corresponding to an elastic undamaged behavior for which the traction increases up to a value $\sigma_{\mathrm{c}}$ corresponding to a characteristic displacement jump $\delta_{0}$. In practice, $\delta_{0}$ is small enough to ensure both a work of separation close to the critical energy release rate and the continuity of the displacement field up to the critical traction $\sigma_{\mathrm{c}}$. This latter condition implies that the artificially introduced stiffness $K_{\mathrm{CZM}}=\frac{\sigma_{c}}{\delta_{0}}$ is high enough so that the overall rigidity of the model is not altered [43]. Following recommendations given in $[43,49]$, we employ $K_{C Z M}=10^{7} \mathrm{MPa} / \mathrm{mm}$. Debonding of the two surfaces occurs when the traction has reached $\sigma_{\mathrm{c}}$ until a critical opening displacement $\delta_{\mathrm{c}}$ for which the traction becomes null, thus corresponding to the nucleation of a crack locally. The area under the traction-separation profile corresponds to the work for separation and creation of free surfaces, equal to $G_{\mathrm{c}}$ for an elastic material with no dissipation effects. The zone for which debonding is occurring but does not attain the critical opening displacement is the fracture process zone. Using $\mathrm{CZM}$, it is mandatory to refine enough the FE mesh in order to properly capture this process zone. The process zone length is generally a fraction of the material characteristic length $\frac{E G_{\mathrm{c}}}{\sigma_{\mathrm{c}}^{2}}[42,43]$. Sufficient mesh refinement along the crack path is ensured so that the fracture process zone is well described. Fig. 8a shows a typical mesh in the case of a straight crack. The FE models include around 100000 degrees of freedom and the typical calculation time is around 10 minutes.

\subsection{Material and fracture parameter estimation procedure}

Inverse procedures for material parameter identification applied to WST often solely concern the macroscopic force-displacement response $[10-14,16,17]$. However, the uniqueness of the solution in the inverse identification procedure is not guaranteed. Indeed, several set of parameters can possibly describe the same macroscopic forcedisplacement curve. For instance, an example of force-displacement response obtained from two FE calculations using the same model excepted for the sets of material and fracture parameters (either a bilinear cohesive zone model with $G_{\mathrm{c}}=0.2 \mathrm{MPa} . \mathrm{mm}, \sigma_{\mathrm{c}}=10 \mathrm{MPa}, E=15 \mathrm{GPa}$, or a trilinear cohesive zone model with $G_{\mathrm{c}}=0.2 \mathrm{MPa} . \mathrm{mm}$, $\sigma_{\mathrm{c}}=17 \mathrm{MPa}, E=14 \mathrm{GPa}$ ) is presented in Fig. 9. From this example, it is clear that the sole force-displacement macroscopic response does not discriminate the local failure process. In addition, a local information such as the crack length variation can be taken into account for a better fracture parameter identification. To this aim, the crack propagation has to be tracked during the test in order to determine the crack length variation, which can be achieved experimentally using DIC [15, 18, 23]. 


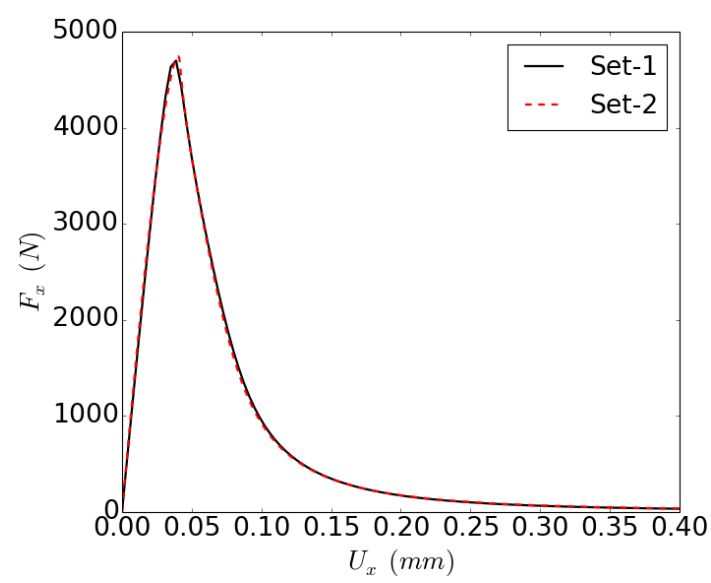

(a)

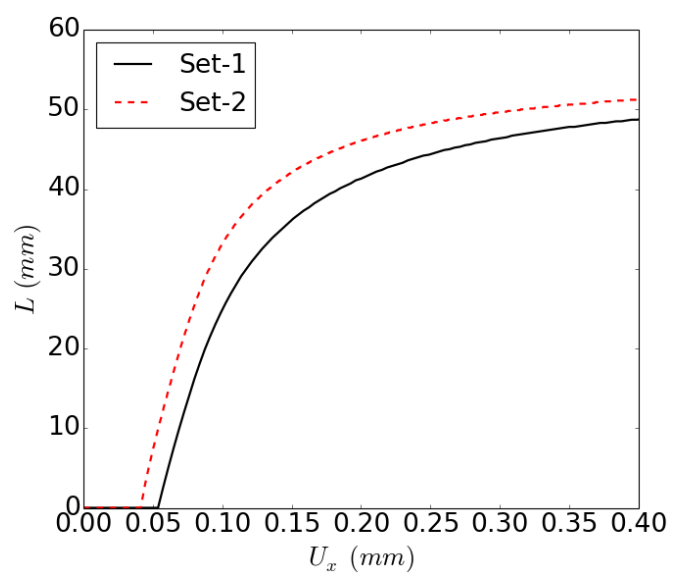

(b)

Fig. 9 (a) Force-displacement responses and (b) crack length variations obtained numerically with two different sets of material and fracture parameters (Set-1: trilinear CZM, $E=14 \mathrm{GPa}, G_{\mathrm{c}}=0.2 \mathrm{MPa} . \mathrm{mm}, \sigma_{\mathrm{c}}=17 \mathrm{MPa}$; Set-2: bilinear CZM, $E=15 \mathrm{GPa}$, $\left.G_{\mathrm{c}}=0.2 \mathrm{MPa} \cdot \mathrm{mm}, \sigma_{\mathrm{c}}=10 \mathrm{MPa}\right)$

The proposed identification procedure consists in determining the material and fracture parameters (Young's Modulus $E$, critical energy release rate $G_{\mathrm{c}}$ and strength $\sigma_{\mathrm{c}}$, the material behavior being considered as isotropic linear elastic) that best fit both the force-displacement response and the crack length variation during the test. Note that Poisson's ratio is not included in the procedure since it has been checked numerically that it has almost no influence on both force and crack length variations. The following problem of minimizing the residuals $R_{T}$ with respect to the material parameters $\left(E, G_{\mathrm{c}}, \sigma_{\mathrm{c}}\right)$ has to be solved:

$$
R_{\mathrm{T}}^{*}=\min _{E, G_{\mathrm{c}}, \sigma_{\mathrm{c}}} R_{\mathrm{T}}\left(E, G_{\mathrm{c}}, \sigma_{\mathrm{c}}\right),
$$

where the total residuals $R_{\mathrm{T}}$ is defined as the weighted sum of the force $\left(R_{\mathrm{F}}\right)$ and crack length $\left(R_{\mathrm{L}}\right)$ residuals:

$$
\left\{\begin{array}{l}
R_{\mathrm{T}}^{2}=\omega R_{\mathrm{L}}^{2}+(1-\omega) R_{\mathrm{F}}^{2} \\
R_{\mathrm{F}}^{2}=\frac{1}{\gamma_{\mathrm{F}}^{2} N_{\mathrm{F}}} \int\left(F^{\exp }(u)-F^{\mathrm{num}}\left(u, E, G_{\mathrm{C}}, \sigma_{\mathrm{C}}\right)\right)^{2} d u \\
R_{\mathrm{L}}^{2}=\frac{1}{\gamma_{\mathrm{L}}^{2} N_{\mathrm{L}}} \int\left(L^{\exp }(u)-L^{\mathrm{num}}\left(u, E, G_{\mathrm{C}}, \sigma_{\mathrm{c}}\right)\right)^{2} d u
\end{array}\right.
$$

In practice, $R_{\mathrm{T}}$ and $R_{\mathrm{L}}$ are computed on the discrete basis of the number of load $\left(N_{\mathrm{F}}\right)$ and crack length $\left(N_{\mathrm{L}}\right)$ data. The force $\left(F^{\mathrm{num}}\right)$ and crack length $\left(L^{\mathrm{num}}\right)$ predicted numerically are interpolated on the basis of the experimental measurements of the force $\left(F^{\exp }\right)$ and crack length $\left(L^{\exp }\right) \cdot \gamma_{\mathrm{F}}$ and $\gamma_{\mathrm{L}}$ respectively are the standard deviations of the load measurement and of the DIC noise. The pre-factors $\frac{1}{\gamma_{\mathrm{F}}^{2} N_{\mathrm{F}}}$ and $\frac{1}{\gamma_{\mathrm{L}}^{2} N_{\mathrm{L}}}$ are chosen so that the expectation value of $R_{\mathrm{T}}$ and $R_{\mathrm{L}}$ are unity when only noise is at play [41]. The weight $\omega$ is chosen equal to $1 / 2$ so that the balance between both residuals is determined by the measure uncertainty on each quantity. A more detailed discussion on the choice of this parameter is proposed in [41]. In the present work, rather than using a gradient descent algorithm to solve the minimization problem, we made the choice to compute the residuals for a given range of parameters. The reasons for this strategy are:

o It is possible to execute several calculations simultaneously, so that the approach is not slower than a gradient descent approach which requires less calculations but that can only be performed successively. 


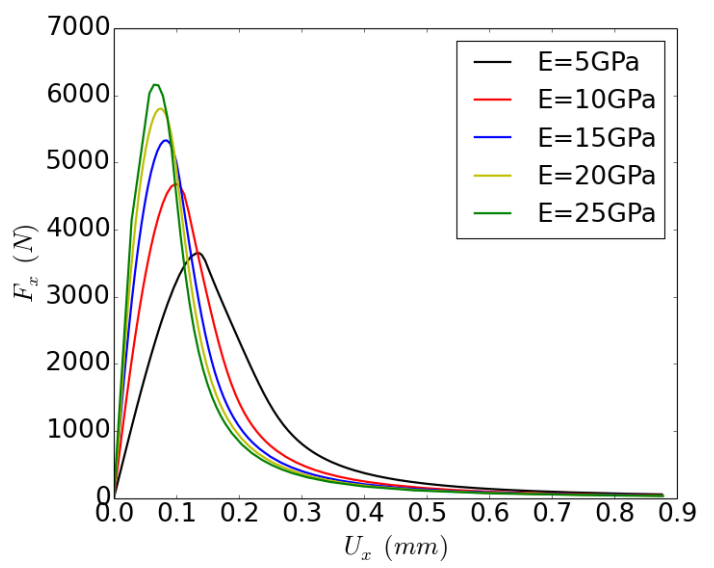

(a)

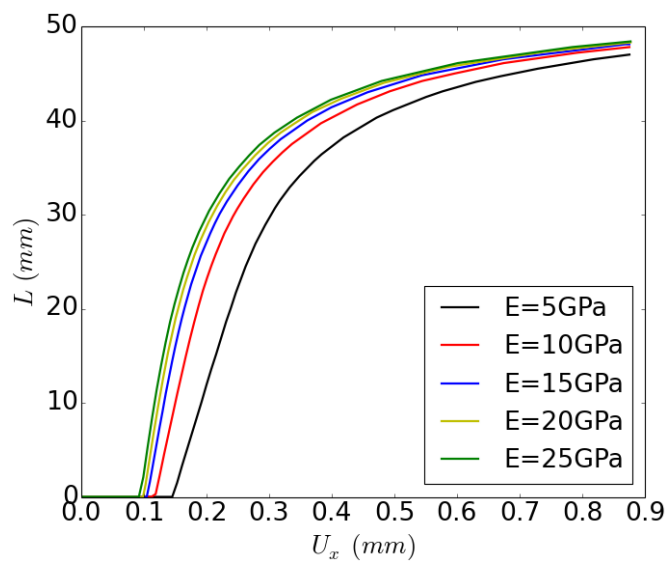

(b)

Fig. 10 (a) Force and (b) crack length variations as a function of prescribed displacement for several Young's modulus values (Other parameters are kept constant).

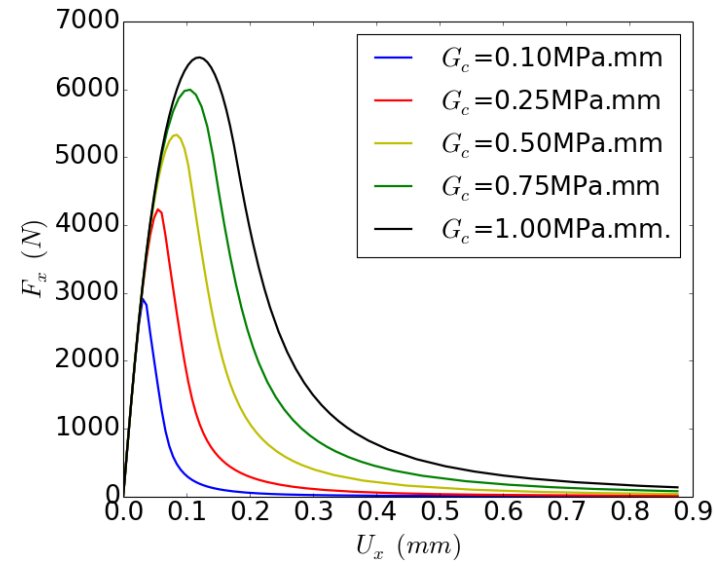

(a)

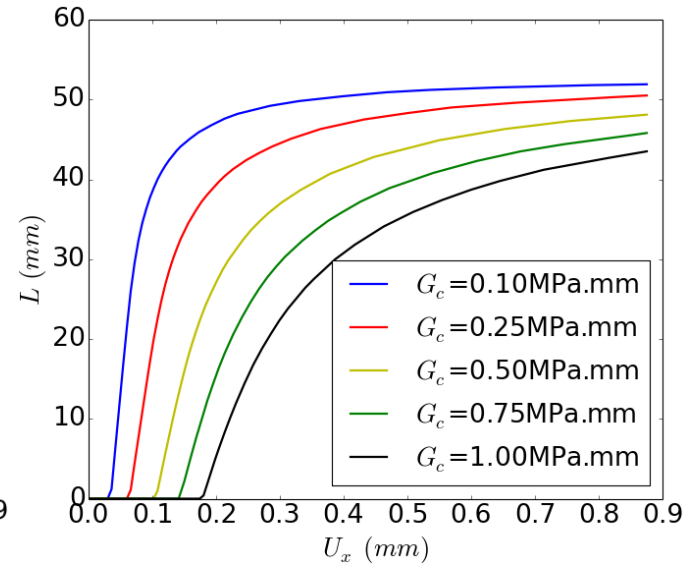

(b)

Fig. 11 (a) Force and (b) crack length variations as a function of prescribed displacement for several critical energy release rate values (Other parameters are kept constant).

o This strategy allows creating a database of calculations, which appears to be really convenient if a lot of specimens have to be tested since it avoids doing the same calculations twice.

o It is less likely to fall in a local minimum than using a gradient descent approach.

\subsection{Sensitivity to material parameters}

The sensitivity to the different material parameters at stake is studied in this section. To this end, the forcedisplacement response and the crack length variations as a function of the prescribed displacement are computed by varying only one parameter among $E, G_{\mathrm{c}}$ and $\sigma_{\mathrm{c}}$ (Fig. 10-12). First, it can be seen from Fig. 10-12 that the slope of the force displacement curve prior to crack nucleation is mainly governed by the material Young's modulus, except near the force maximum value around which a slight nonlinearity appears corresponding to the process zone development prior to crack initiation. Therefore, the material Young's modulus $E$ can be identified separately from the other parameters using only the elastic part of the force-displacement curve. The material critical energy release rate $G_{\mathrm{c}}$ influences the crack length variation and the force maximum. It is also related to the area under the force displacement curve contrary to the material strength $\sigma_{\mathrm{c}}$ that has an influence on the crack 


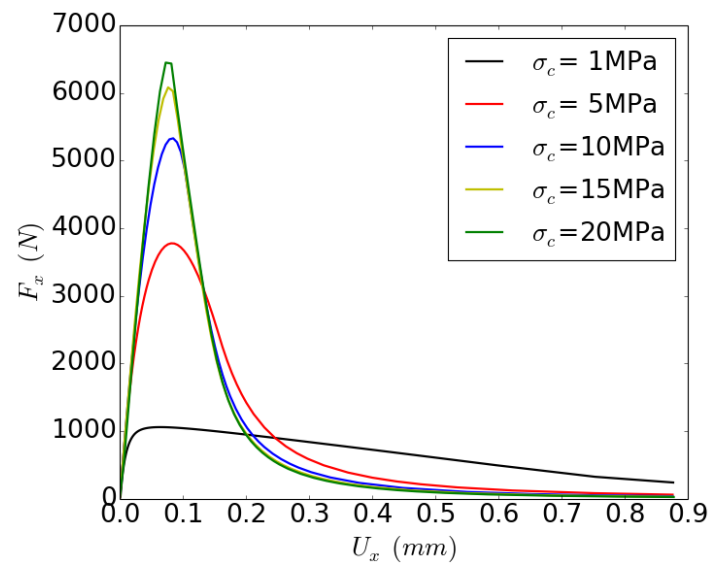

(a)

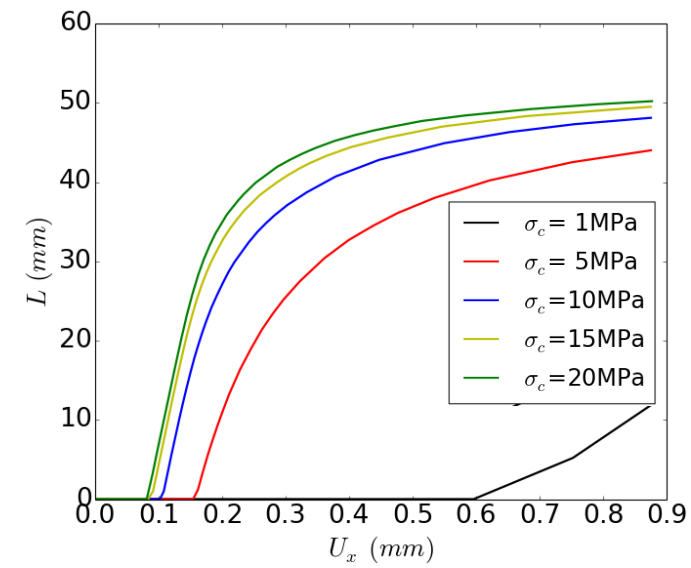

(b)

Fig. 12 (a) Force and (b) crack length variations as a function of imposed displacement for several strength values (Other parameters are kept constant).

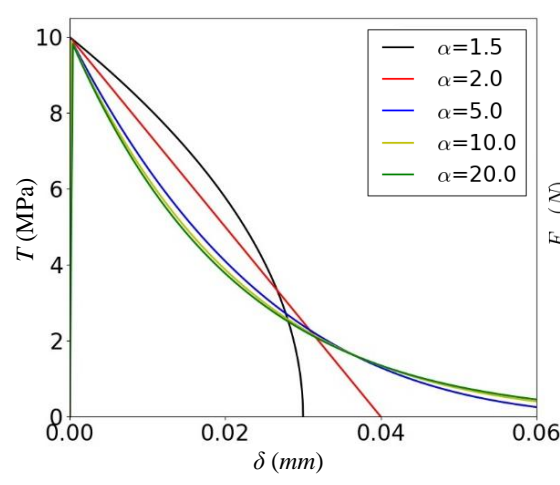

(a)

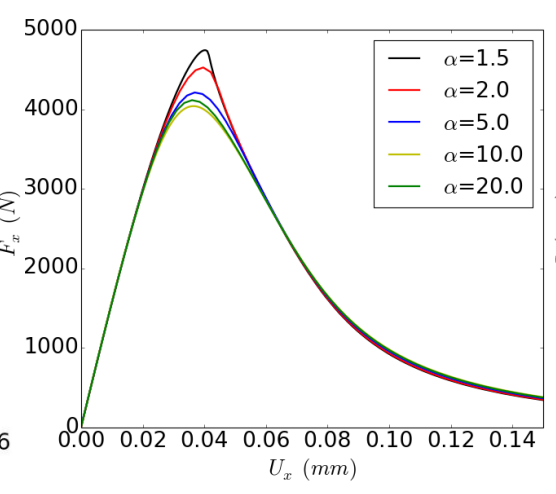

(b)

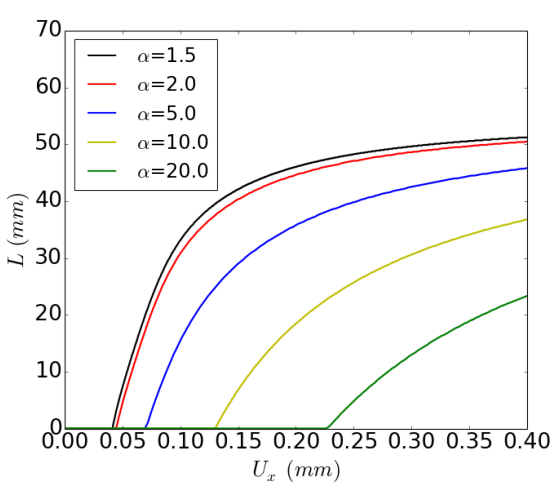

(c)

Fig. 13 (a) Force and (b) crack length variations as a function of imposed displacement for several CZM profiles with constant fracture parameters $G_{\mathrm{C}}$ and $\sigma_{\mathrm{c}}$.

length variation, the force maximum and the force-displacement profile. Since the material Young's modulus can be identified separately from the other parameters, for a given CZM profile, the residuals only have to be computed as a function of two parameters $\left(G_{\mathrm{c}}\right.$ and $\left.\sigma_{\mathrm{c}}\right)$, which leads to a reasonable number of calculations to perform in order to solve the minimization problem.

\subsection{Sensitivity to cohesive zone profile}

In addition to $G_{\mathrm{c}}$ and $\sigma_{\mathrm{c}}$, the profile of the traction-separation law of the cohesive zone model can be varied. Classical profiles that are usually employed are, e.g., Dudgale's model [42], exponential laws [44,45], bilinear [46] or trilinear softening. Park et al. $[47,48]$ proposed a versatile CZM formulation which allows different traction separation profiles to be modeled by adjusting a single shape parameter $\alpha$ (for fixed fracture parameters $\sigma_{\mathrm{c}}$ and $\left.G_{\mathrm{c}}\right)$. The mathematical definition of $\alpha$ is given in $[47,48]$. Dudgale model is retrieved when $\alpha$ tends towards 1 , a bilinear model is obtained if $\alpha=2$ and $\alpha>2$ results in a trilinear-like model. Fig. 13 shows the influence of the CZM profile on the force-displacement response and crack length variation. On the one hand, the CZM profile 


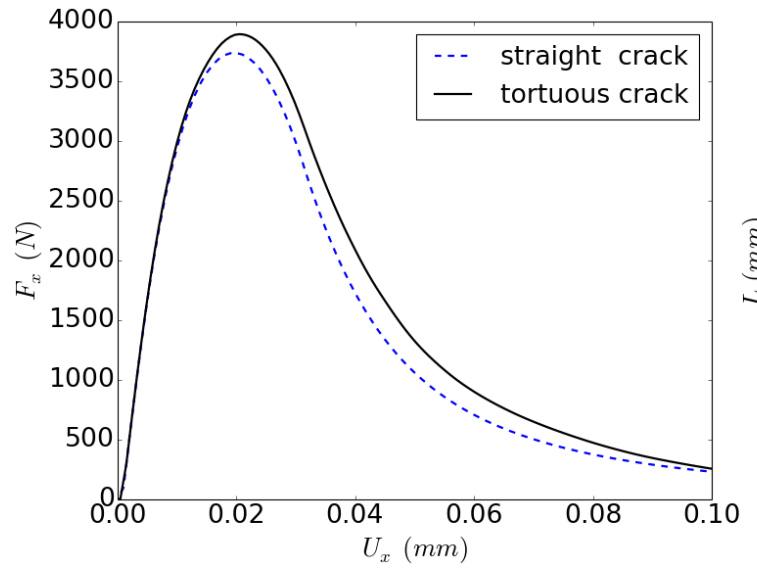

(a)

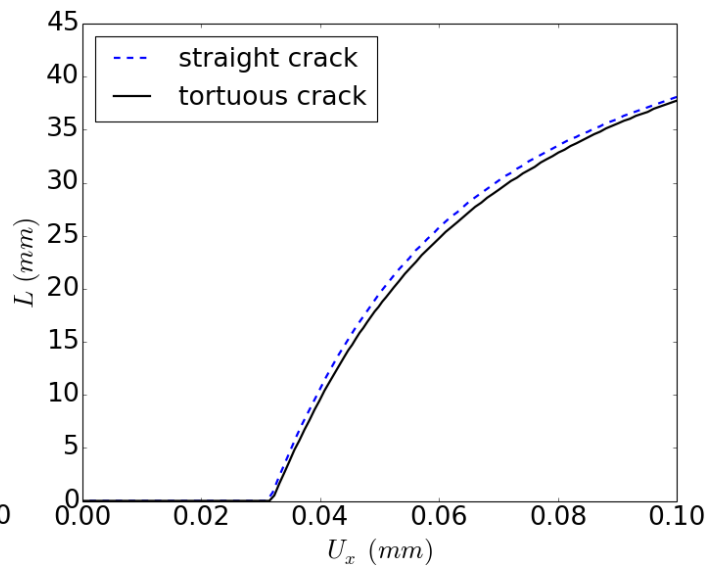

(b)

Fig. 14 (a) Force and (b) crack length (projected along (Oy) axis, $c f$. Fig. 8) variations as a function of imposed displacement for a straight or a tortuous crack.

seems to have a rather small influence on the force-displacement response, except around the force maximum which corresponds to crack initiation. Similar results were found in $[16,46,49]$, which is consistent with the conclusion of Acary and Monerie [50] who showed that all the CZM are equivalent for stable rectilinear crack propagation (in an infinite medium) but not for initiation and branching. On the other hand, it can be observed that the CZM profile has a strong influence on the crack length variation as a function of the imposed displacement. This results also motivates the combination of both a residuals on force and a residuals on crack length in the case the CZM profile is not known a priori. In the following, we choose to adopt a bilinear CZM profile. The traction separation profile thus reads:

$$
T= \begin{cases}K_{\mathrm{CZM}} \delta & \text { if } \delta \leq \frac{\sigma_{c}}{K_{\mathrm{CZM}}} \\ \left(\frac{\delta_{c}-\delta}{\delta_{c}-\frac{\sigma_{c}}{K_{\mathrm{CZM}}}}\right) \sigma_{c} & \text { if } \frac{\sigma_{c}}{K_{\mathrm{CZM}}} \leq \delta \leq \delta_{c} \\ 0 & \text { if } \delta \geq \delta_{c} .\end{cases}
$$

\subsection{Sensitivity to crack tortuosity}

Experimentally, the studied specimens do not present any groove to guide the crack, as it is the case, e.g., in $[11,15]$. Therefore, a non rectilinear crack propagation might be observed because of microstructure effects or a slight asymmetry in the loading. The crack tortuosity can be taken into account in the numerical model. The crack path observed experimentally is computed by thresholding the strain fields obtained using DIC. This crack path is then taken into account during the meshing step of the specimen ( $c f$. Fig. 8b). Of course, since only surface observations using DIC were performed experimentally, this is only a $2 \mathrm{D}$ representation of the crack path observed on the surface of the specimen. Taking into account the real crack path would require volume observations such as tomography and a 3D FE model. The force and crack length variations in the case of a straight or tortuous crack are presented in Fig. 14. Both configurations lead to similar profiles of crack length variation and forcedisplacement, the latter being slightly underestimated if a straight crack is modeled. Modeling a straight crack instead of a meandering one, of course, an approximation in the numerical model. In the present case, the same force-displacement response as in the case of a tortuous crack could be retrieved with a straight crack by raising 


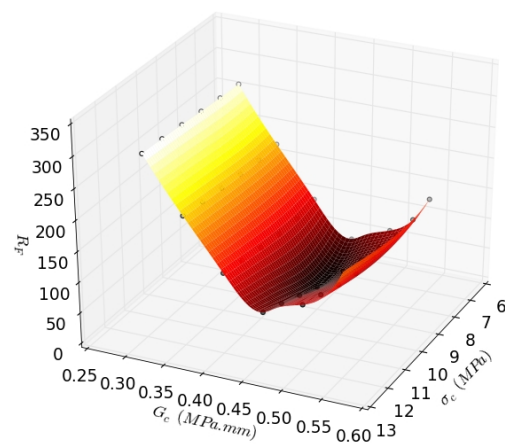

(a)

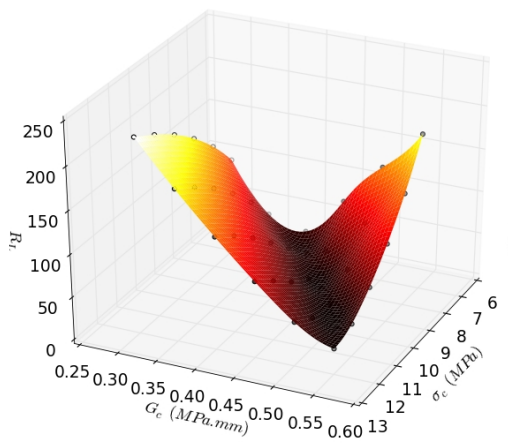

(b)

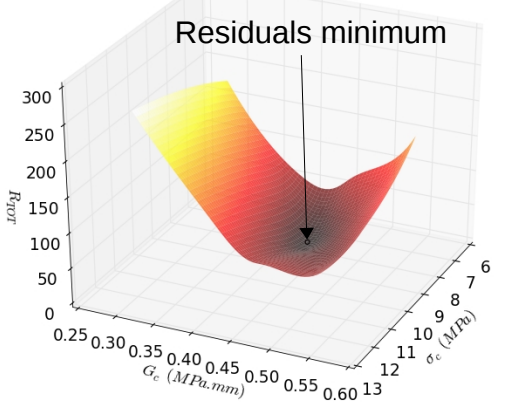

(c)

Fig. 15 (a) Force, (b) crack length, and (c) total residuals as a function of the fracture parameters $G_{\mathrm{c}}$ and $\sigma_{\mathrm{c}}$.

the value of $G_{\mathrm{C}}$ by around $10 \%$. If a straight crack is modeled rather than the actual $2 \mathrm{D}$ crack path observed on the specimen surface, the identified values of the fracture parameters thus account for the possible crack deviation from a straight path as well as micro-cracks that may be present near the main crack $[9,18]$. As stated in the introduction, one of the objectives of the fracture parameter identification is to perform structure calculations at the scale of a glass furnace subjected to high thermal gradient. Therefore, the approximation of a straight crack seems reasonable in the sense that features such as local deviation of the crack or microcracks around a main crack would not be modeled at such a scale.

\section{Identification of fracture parameters}

In this section, the proposed identification procedure is applied to :

o A virtual experiment for which a FE calculation is used to generate data so as to validate the proposed method.

o Three real experiments on an industrial refractory from $25^{\circ} \mathrm{C}$ to $1200^{\circ} \mathrm{C}$.

\subsection{Inverse identification on a virtual WST experiment}

The reliability of the method is first studied by generating virtual experiment data from a numerical calculation. The chosen parameters are $E=12.35 \mathrm{GPa}, G_{\mathrm{c}}=0.455 \mathrm{MPa} . \mathrm{mm}$ and $\sigma_{\mathrm{c}}=9.1 \mathrm{MPa}$. Some noise is independently added to the computed force and crack length variations as a function of the prescribed displacement so as to obtain data representative of a real test. The identification procedure presented in Section 3.2 is applied to this test case. Fig. 15 shows the force, crack length and total residuals variation as a function of the fracture parameters $G_{\mathrm{c}}$ and $\sigma_{\mathrm{c}}$. It can be observed that both the force and crack length residuals present a valley corresponding to different parameter couples, the combination of both residuals leading to the determination of the parameter couple that best fit the virtual experiment data. The identified parameters are $E=12.4 \mathrm{GPa}, G_{\mathrm{c}}=0.448 \mathrm{MPa} . \mathrm{mm}$ and $\sigma_{\mathrm{c}}=8.7 \mathrm{MPa}$, which are close to the input parameters used to generate the virtual experiment. Fig. 16 shows the force and crack length variation as a function of the prescribed displacement obtained using the set of identified parameters together with the generated virtual experimental data. A good agreement is obtained between the generated virtual data and the predictions obtained with the identified parameters. 


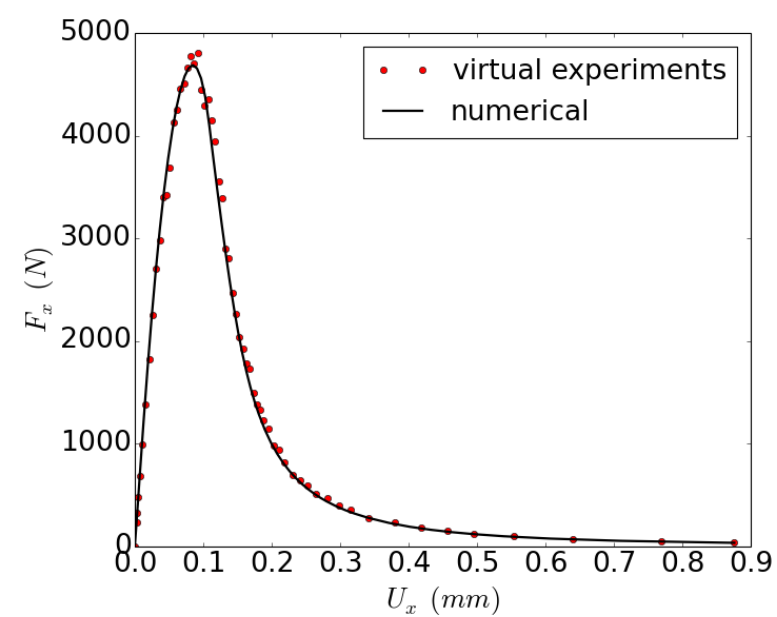

(a)

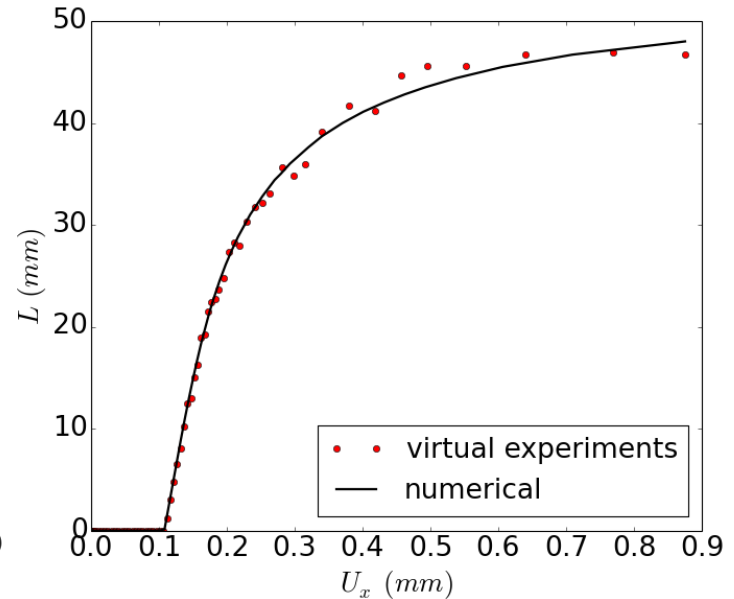

(b)

Fig. 16 (a) Force and (b) crack length variations as a function of imposed displacement generated by adding some noise to reference calculation results (virtual experiments) and obtained numerically using the parameters determined by the inverse identification procedure.

\subsection{Inverse identification on an industrial refractory from $25^{\circ} \mathrm{C}$ to $1200^{\circ} \mathrm{C}$}

The identification procedure is now applied to the tests already presented with the industrial refractory from $25^{\circ} \mathrm{C}$ to $1200^{\circ} \mathrm{C}$ (Section 2). Fig. 17 shows the force and crack length variation as a function of the imposed displacement obtained experimentally for the specimen tested at $800{ }^{\circ} \mathrm{C}$ and numerically with the set of parameters obtained from the inverse identification procedure. The property estimates that best fit experimental data are $E=38 \mathrm{GPa}$, $G_{\mathrm{c}}=0.107 \mathrm{MPa} . \mathrm{mm}$ and $\sigma_{\mathrm{c}}=5.2 \mathrm{MPa}$. It can be noted that the material under investigation is a refractory ceramic containing oxides that is used for glass furnace. This is similar to the materials studied, for instance, in $[6,9,11,18,23]$ exhibiting Young's modulus in the same order of magnitude as the one obtained herein. A reasonable agreement is obtained between experimental and numerical force and crack length variations, even if the predicted force slightly deviates from experimental results from a certain imposed displacement. A possible explanation to this difference is that in the calculation, the crack is allowed to break the specimen into two parts so that the force decreases to zero. However, in the experiments, the crack does not propagate until the specimen end so that such a decrease of the force is not observed. This is likely to originate from $3 \mathrm{D}$ branching of the main crack or microcrack creation in the process zone around the main crack that are energetically more favorable than the propagation of the main crack. Taking into account such phenomena would require a 3D characterization of the specimen using, for instance, tomography and also 3D modeling of crack propagation. From a phenomenological point of view, it is possible to retrieve the same force-displacement response as in the experiments by artificially raising the critical energy release rate (from $0.107 \mathrm{MPa} . \mathrm{mm}$ to $0.175 \mathrm{MPa} . \mathrm{mm}$ in the present case) in the bottom part of a specimen. The same identification procedure is applied at $25^{\circ} \mathrm{C}$ and $1200^{\circ} \mathrm{C}$, the property estimates are gathered in Table 1 and the corresponding CZM profiles are plotted in Fig. 18. One can notice how the material fracture energy increases with increasing temperature, so that the material becomes more resistant to propagation as the crack is closed from the hot zones in application. Based on these properties, an estimate of the FPZ size can be computed based on the so-called Hillerborg value $l_{\mathrm{H}}=\frac{E G_{\mathrm{c}}}{\sigma_{\mathrm{c}}^{2}}($ the FPZ size usually being a fraction of this length [43]) showing that the FPZ at high temperature is probably not fully developed given the size of these WST samples. Using 


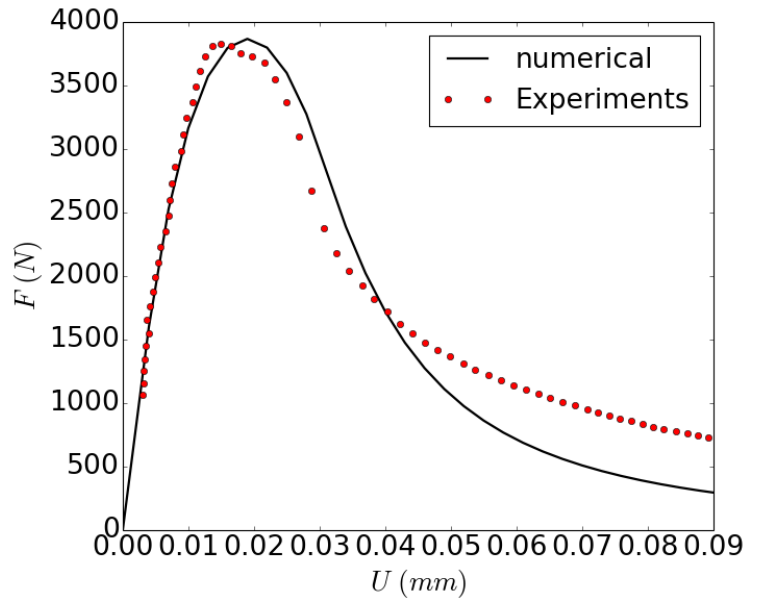

(a)

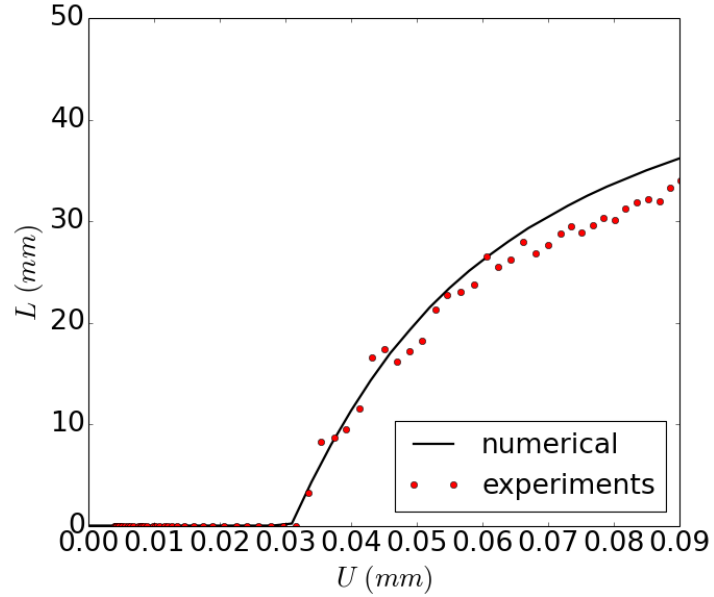

(b)

Fig. 17 (a) Force and (b) crack length variations as a function of imposed displacement measured experimentally at $800^{\circ} \mathrm{C}$ and obtained numerically using the parameters determined by the inverse identification procedure.

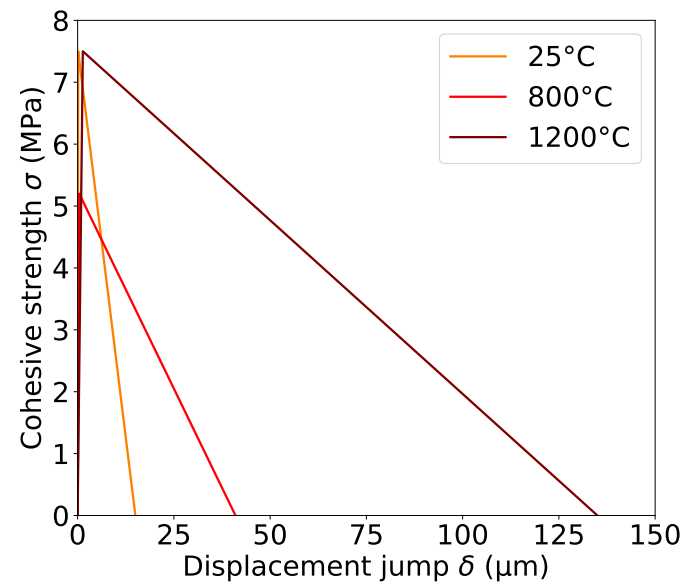

Fig. 18 Identified CZM laws depending on the temperature

larger samples would enable a full development of the process zone and thus of the toughening mechanisms during the fracture of the refractory.

\begin{tabular}{|c|c|c|c|}
\hline $\mathrm{T}\left({ }^{\circ} \mathrm{C}\right)$ & 25 & 800 & 1200 \\
\hline$E(\mathrm{GPa})$ & 28 & 38 & 22 \\
$G_{\mathrm{c}}(\mathrm{MPa} . \mathrm{mm})$ & 0.057 & 0.107 & 0.506 \\
$\sigma_{\mathrm{c}}(\mathrm{MPa})$ & 7.5 & 5.2 & 7.5 \\
\hline$l_{\mathrm{H}}(\mathrm{mm})$ & 28 & 150 & 197 \\
\hline$\delta_{\mathrm{c}}(\mathrm{mm})$ & 0.015 & 0.041 & 0.135 \\
\hline
\end{tabular}

Table 1 Identified CZM properties depending on the temperature

\section{Conclusion}

Ceramic refractory fracture parameter identification based on a WST at high temperature brings experimental challenges, especially employing DIC but it allows the crack propagation to be tracked during the test, which brings a supplementary local information to the macroscopic force-displacement response usually employed in WST 
analysis. Combining both force and crack length residuals in an inverse identification procedure allows a better discrimination of some material parameter configurations leading to the same force-displacement response. The definition of the crack length measured experimentally has to be coincident with that used in the numerical model. In the case where cohesive zone models are employed, the displacement jump along the presupposed crack path has to be measured by DIC in order to define the crack as the zone for which the displacement jump overcomes a critical value. Based on these data, the material Young's modulus may be identified separately using the elastic part of the force-displacement curve before the two fracture parameters can be determined by indirect confrontation to experimental data as the parameters minimizing the combination of force and crack length residuals. The method has been validated with virtual experiment data generated by adding some noise to a calculation result. Reasonable agreements are obtained in the case of a WST on a ceramic refractory from $25^{\circ} \mathrm{C}$ to $1200^{\circ} \mathrm{C}$, including some differences probably due to 3D effects such as crack branching not accounted for in the present model. The identified properties demonstrate the increasing resistance of this material to crack propagation with increasing temperature, a key property for industrial applications. The use of this method coupling several experimental and numerical tools represents a significant advantage to understand and optimize the fracture behaviour of industrial refractories.

\section{Acknowledgements}

The authors would like to thank Saint-Gobain SefPro for providing the refractory samples and supporting this work carried out at Saint-Gobain Research Provence thanks to the experimental facilities of the LAP (Laboratoire Application Physique).

\section{References}

1. Bruhwiler, E., Wittmann, F.H., 1990. The wedge splitting test, a new method of performing stable fracture mechanics test. Eng. Fract. Mech. 35(1-3), pp 117-125.

2. Hu, X.Z., Wittman, F.H.,1992. Fracture energy and fracture process zone. Mater. Struct. 25, pp 319-326.

3. Tschegg, E.K.,1991. New equipments for fracture tests on concrete. Mater. Test. 33, pp 338-342.

4. Harmuth, H.,1995. Stability of crack propagation associated with fracture energy determined by wedge splitting specimen, Theoret. Appl. Fract. Mech. 23, pp 103-108.

5. Harmuth, H., Rieder, K.A., Krobath M., Tschegg E.K.,1996. Investigation of the nonlinear fracture behavior of ordinary ceramic refractory materials. Mater. Sci. Engng. A 214, pp 53-61.

6. Harmuth, H., Tschegg E.K.,1997, A fracture mechanics approach for the development of refractory materials with reduced brittleness. Fatigue. Fract. Engng. Mater. Struct. 20(11),pp 1585-1603.

7. Rieder, K.A., Tschegg E.K., Harmuth, H.,1998. Notch sensitivity of ordinary ceramic refractory materials. J. Mater. Sci. Lett. 17, pp 675-678.

8. Belrhiti, Y., Pop, O., Germaneau, A., Doumalin, P., Dupré, J.C., Harmuth, H., Huger, M., Chotard, T.,2015. Investigation of the impact of micro-cracks on fracture behavior of magnesia products using wedge splitting test and digital image correlation. J. Eur. Cer. Soc. 35, pp 823-829.

9. Dai, Y., Gruber D., Harmuth, H.,2017. Determination of the fracture behaviour of MgO-refractories using multi-cycle wedge splitting test and digital image correlation. J. Eur. Cer. Soc. 37, pp 5035-5043.

10. Abdalla, H.M., Karihaloo, B.L., 2004. A method for constructing the bilinear tension softening diagram of concrete corresponding to its true fracture energy. Mag. Concr. Res. 10, pp 597-604. 
11. Jin, S., Gruber D., Harmuth, H., 2014. Determination of Young's modulus, fracture energy and tensile strength of refractories by inverse estimation of a wedge splitting procedure. Engng. Fract. Mech. 116, pp 228-236.

12. Kim, J., Lee, Y., Yi, S., 2004. Fracture characteristics of concrete at early ages. Cem. Concr. Res. 34, pp 507-519.

13. Lofgren, I., Stang, H., Olesen, J.F., 2005. Fracture properties of FRC determined through inverse analysis of wedge splitting and three-point bending tests. J Adv Concr Technol 3, pp 423-434.

14. Skoček, J., Stang, H.,2008. Inverse analysis of the wedge splitting test. Engng. Fract. Mech. 75, pp 3173-3188.

15. Vargas, R., Neggers, J., Canto, R.B., Rodrigues, J.A., Hild, F., 2018. Comparison of two full-field identification methods for the wedge splitting test on a refractory. J. Eur. Cer. Soc. 38, pp 5569-5579.

16. Vargas, R., Neggers, J., Canto, R.B., Rodrigues, J.A., Hild, F., 2019. Analysis of a castable refractory using the wedge splitting test and cohesive zone model. J. Eur. Cer. Soc., doi:10.1016/j.jeurceramsoc.2019.03.009

17. Auer, T., Harmuth, H, 2006. Numerical simulation of a fracture test for brittle disordered materials. In: Gdoutos EE, editor. Fracture of nano and engineering materials and structures. Proceedings of the 16th European conference of fracture, Alexandroupolis. pp. 591-592.

18. Dai, Y., Gruber D., Harmuth, H.,2017. Observation and quantification of the fracture process zone for two magnesia refractories with different brittleness. J. Eur. Cer. Soc. 37, pp 2521-2529.

19. Doitrand, A., Fagiano, C., Hild, F., Chiaruttini, V., Mavel, A., Hirsekorn, M., 2017. Mesoscale analysis of damage growth in woven composites. Compos. A 96, pp 77-88.

20. Besnard, G., Hild, F., Roux, S., 2006. Finite-element displacement fields analysis from digital images: application to Portevin-Le Chatelier bands. Exp. Mech., 46(6), 789-803.

21. Leplay, P., Lafforgue, O., Hild, F., 2015. Analysis of asymmetrical creep of a ceramic at 1350C by digital image correlation. J. Ame. Cer. Soc., 98(7), 2240-2247.

22. Pan, B., Wu, D., Wang, Z., Xia, Y., 2010, High-temperature digital image correlation method for full-field deformation measurement at 1200C. Meas. Sci. Tech. 22(1), 015701.

23. Dupré, J.C., Doumalin, P., Belrhiti, Y., Khlifi, I., Pop, O., Huger, M., 2015. Detection of cracks in refractory materials by an enhanced digital image correlation technique. J. Mater. Sci. 53, pp 977-993.

24. Lyons, J. S., J. Liu, and M. A. Sutton. "High-temperature deformation measurements using digital-image correlation." Exp. Mech. 36(1) (1996): 64-70.

25. Grant, B. M. B., et al. "High-temperature strain field measurement using digital image correlation." J. Strain Anal.Engng. Des. 44(4) (2009): 263-271.

26. Dong, Y. L., Pan, B., 2017, A review of speckle pattern fabrication and assessment for digital image correlation. Exp. Mech. $57(8), 1161-1181$.

27. Song, J., Yang, J., Liu, F., Lu, K., 2018. High temperature strain measurement method by combining digital image correlation of laser speckle and improved RANSAC smoothing algorithm. Opt. Las. Engng. 111, 8-18.

28. Hammer, J. T., Seidt, J. D., Gilat, A., 2014. Strain measurement at temperatures up to 800 C utilizing digital image correlation. In Advancement of Optical Methods in Experimental Mechanics, 3, 167-170.

29. Gazeau, C., Gillibert, J., Blond, E., Geffroy, P. M., Richet, N.,2015. Experimental set up for the mechanical characterization of plane ITM membrane at high temperature. J. Eur. Cer. Soc. 35(14), 3853-3861.

30. Reu, P. L., Jones, E. M. C., 2019. Eliminating Air Refraction Issues in DIC by Conducting Experiments in Vacuum. In Advancement of Optical Methods and Digital Image Correlation in Experimental Mechanics, Volume 3 (pp. 85-87).

31. Su, Y. Q., Yao, X. F., Wang, S., Ma, Y. J., 2015. Improvement on measurement accuracy of high-temperature DIC by grayscaleaverage technique. Opt. Las. Engng. 75, 10-16.

32. Berny, M., Archer, T., Mavel, A., Beauchene, P., Roux, S., Hild, F., 2018, On the analysis of heat haze effects with spacetime DIC. Opt. Las. Engng. 111, 135-153.

33. Chi, Y., Pan, B., 2018, Spatial-Temporal Digital Image Correlation: A Unified Framework, Computer Vision and Pattern Recognition, arXiv:1812.04826v2

34. Wang, X., Liu, X., Zhu, H., Ma, S., 2017. Spatial-temporal subset based digital image correlation considering the temporal continuity of deformation. Opt. Las. Engng. 90, 247-253. 
35. Delmas, A., Le Maoult, Y., Buchlin, J. M., Sentenac, T., Orteu, J. J., 2013. Shape distortions induced by convective effect on hot object in visible, near infrared and infrared bands. Exp. Flu. 54(4), 1452.

36. Jones, E. M. C., Reu, P. L., 2018. Distortion of Digital Image Correlation (DIC) Displacements and Strains from Heat Waves. Exp. Mech., 58(7), 1133-1156.

37. Réthoré, J., Hild, F., Roux, S., 2008. Extended digital image correlation with crack shape optimization. Int. J. Num. Meth. Engng, 73(2), 248-272.

38. Réthoré, J., Roux, S., Hild, F., 2009. An extended and integrated digital image correlation technique applied to the analysis of fractured samples: The equilibrium gap method as a mechanical filter. Eur. J. Comp. Mech. 18(3-4), 285-306.

39. I. Khlifi, J.C.Dupré, P.Doumalinb Y. Belrhiti, O. Pop, M.Huger, 2017. Improvement of Digital Image Correlation for the analysis of the fracture behaviour of Refractories, 23eme Congrès Français de Mécanique.

40. Leplay, P., Réthoré, J., Meille, S., Baietto, M. C., 2011. Identification of damage and cracking behaviours based on energy dissipation mode analysis in a quasi-brittle material using digital image correlation. Int. J. Fract. 171(1), 35.

41. Mathieu, F., Leclerc, H., Hild, F., Roux, S., 2015. Estimation of Elastoplastic Parameters via Weighted FEMU and IntegratedDIC. Experimental Mechanics 55, pp 105-119.

42. Dugdale, D.S., 1960. Yielding of steel sheets containing slits. J. Mech. Phys. Sol 8, pp 100-104.

43. Turon, A., Dávila, C.G., Camanho, P.P., Costa, J., 2007. An engineering solution for mesh size effects in the simulation of delamination using cohesive zone models. Engng. Fract. Mech. 74, pp 1665-1682.

44. Tvergaard, V., Hutchinson, J.W., 1992. The relation between crack growth resistance and fracture process parameters in elastic-plastic solids. J. Mech. Phys. Sol. 40, pp 1377-1397.

45. Xu, X., Needleman, A., 1994. Numerical simulations of fast crack growth in brittle solids. J. Mech. Phys. Sol. 42 , pp 1397-1434.

46. Alfano, G., 2006. On the influence of the shape of the interface law on the application of cohesive-zone models. Compos. Sci. Tech 66, pp 723-730.

47. Park, K., Paulino, G.H., Roesler, J.R., 2009. A unified potential-based cohesive model of mixed-mode fracture. J. Mech. Phys. Sol. 57, pp 891-908.

48. Park, K., Paulino, G.H., 2012. Computational implementation of the PPR potential-based cohesive model in ABAQUS: Educational perspective. Engng. Fract. Mech. 93, pp 239-262.

49. Doitrand, A., Estevez, R., Leguillon, D., 2019. Comparison between cohesive zone and coupled criterion modeling of crack initiation in rhombus hole specimens under quasi-static compression. Theoret. Appl. Fract. Mech. 99, pp 51-59.

50. Acary, V., Monerie, Y., 2006. Nonsmooth fracture dynamics using a cohesive zone approach. Research Report RR-6032, INRIA.

51. Su, H., Fang, X., Qu, Z., Zhang, C., Yan, B., Feng, X., 2016. Synchronous full-field measurement of temperature and deformation of $\mathrm{C} / \mathrm{SiC}$ composite subjected to flame heating at high temperature. Experimental Mechanics, 56(4), pp 659-671.

52. Qu, Z., Fang, X., Su, H., Feng, X, 2015. Measurements for displacement and deformation at high temperature by using edge detection of digital image. Applied optics, 54(29), pp 8731-8737. 